\title{
A Comparison of Dispersal Traits in Dandelions Growing in Urban Landscape and Open Meadows
}

\author{
H. S. Arathi ${ }^{1}$ \\ ${ }^{1}$ Department of Biology, Colorado State University, USA \\ Correspondence: H. S. Arathi, Department of Biology, Colorado State University, USA. Tel: 1- 970- 491 -0952. \\ E-mail: arathi@lamar.colostate.edu
}

Received: June 9, 2012 Accepted: July 14, 2012 Online Published: July 16, 2012

doi:10.5539/jps.v1n2p40

URL: http://dx.doi.org/10.5539/jps.v1n2p40

\begin{abstract}
The highly fragmented nature of habitats for plant growth in the urban landscape offers unique challenges to these plants and some weedy species have been particularly successful in exploiting these urban habitats. The common dandelion, Taraxacum officinale, is one such highly successful weed that grows profusely in both urban landscapes and open meadows. In this study, the growth, flowering intensity and achene and seed morphology of urban and meadow dandelions were compared. Achenes from urban plants showed higher germination and flowering success, producing significantly higher number of flowers. Achene morphology differed significantly between the two populations such that urban achenes have longer pappus beaks than their meadow counter parts. Urban achenes also dropped quickly to the ground limiting their dispersal capacity from the maternal plant. Morphological traits of urban dandelion achenes are likely to allow for enhanced survival under variable environments in the urban landscapes. Dandelions have been shown to be highly successful and especially capable of adjusting to different environmental pressures which may be the key to their success in colonizing diverse habitats all across the world including urban environments that constantly undergo modification.
\end{abstract}

Keywords: achene, common dandelion, dispersal, habitat fragmentation, pappus, Taraxacum officinale

\section{Introduction}

Current trends in urbanization have led to an increase in small and fragmented habitats for plant growth. These small soil patches are generally surrounded by asphalt and concrete restricting plant growth to the small fragments that are akin to 'urban islands' (Shochat, Warren, Faeth, McIntyre, \& Hope, 2006). Plant populations that can grow in these 'urban islands' tend to be small and relatively closed (Aviron, Kindlmann, \& Burel, 2007; Steffan-Dewenter \& Tscharntke 1999) experiencing selection pressures similar to those on oceanic islands. Survival of seeds and fitness gain from the dispersal potential of wind-dispersed achenes tend to be limited. Not all plant species have been able to adapt to these pressures, but some weedy ones have been extremely successful in colonizing these fragmented habitats (Ogawa \& Mototani, 1991; Cheptou, Carrue, Rouifed, \& Cantarel 2008; Ozinga et al., 2009). Population dynamics models predict that the probability of survival in fragmented landscapes is greatly affected by dispersal rates. Thomas (2000) and Cheptou et al. (2008) have shown that urban populations of the weed, Crepis sancta produce larger proportions of non-dispersing seeds as compared to the open, rural populations allowing the plant to maintain a sustainable population in the urban habitats.

Dispersal is a ubiquitously critical trait for species establishment, colonization and range expansion in all organisms and has been modeled as a cost-benefit process (Levin, Muller-Landau, Ran, \& Jerome, 2003). The costs of dispersal include arriving at sites limited in resources while the corresponding benefits comprise of reduced competition, especially that from kin. Some theoretical models predict that dispersal continues to be advantageous even under conditions when mortality due to dispersal is very high and a stable dispersal strategy is not optimal (Hamilton \& May, 1977). Minimizing dispersal rates may be beneficial when suitable habitats are limited in number or when overall habitat quality remains constant and negates the need for finding better ones. Accordingly, loss or alterations in dispersal-related traits are common in organisms adapting to islands as they become endemics (Cody \& Overton, 1996; Roff, 1990). In plants that disperse via seeds, such alterations include a reduction or lack of plumes in wind-dispersed seeds, smaller awns or hooks in animal dispersed seeds, and an overall increase in fruit and seed size. 
The common dandelion, Taraxacum officinale, has spread from Europe to North America and Asia over the last century (Solbrig, 1971), evolving traits that have contributed to its success (Richards, 1973). It has outcompeted native species in diverse habitats including sub-alpine conditions in North America (Brock, Weinig, \& Galen 2005) and metropolitan areas in Asia (Ogawa \& Mototani, 1991). Studies have previously shown the superior performance of the introduced T. officinale over that of the native T. ceratophorum (Brock, Weinig, \& Galen 2005), T. californicum (Lyman \& Ellstrand, 1998) and T. japonicum (Kandori, Hirao, Matsunaga, \& Kurosaki, 2009). Given that $T$. officinale is well distributed in both urban areas and open meadows, this study examines the dispersal traits of plants from these different habitats to determine any variation that may favor population establishment under vastly different growing environments by 1) characterizing the morphological traits of achenes collected from distinct populations in urban and meadow habitats of $T$. officinale to determine relations with dispersal potential, and 2) monitoring their performance under greenhouse conditions to determine differences in their growth and flowering traits in a common neutral environment.

\section{Materials and Methods}

Taraxacum officinale (L.)Weber, the common dandelion produces compound inflorescences consisting of many florets on a flat pad at the end of a hollow scape arising from the base of the plant. The life history of the common dandelions varies from annual monocarpic to annual polycarpic sexually reproducing or apomictic plants (Dijk, 2003). Mature infructescences appear as spherical balls with many single seeded fruits called achenes which are the dispersal units (diaspores). These achenes are dislodged from the mature head and disperse to different sites mainly by wind. Each achene is carried by the attached pappus disk that serves as a parachute and the elongated shaft (pappus beak) between the two breaks off upon landing, separating the achene from the hairy pappus. If the achene lands on a suitable surface it can either germinate immediately or become part of a long-term seed bank (Ridley, 1930).

Mature infructescences were collected and stored in individual containers. Their scape lengths were measured before collection to obtain an estimate of the release height of each achene. A total of 135 plants from 5 different urban populations and 146 plants from 5 different open meadows, designated as meadow populations, were collected. The urban populations with several hundred plants were located along roadsides in residential areas at least $5 \mathrm{~km}$ away from the meadow populations and consisted of many isolated patches generally less than $1 \mathrm{~m}^{2}$ in area and over $20 \mathrm{~m}$ apart from each other. The urban populations in this study are not recent introductions making them true urban populations that have evolved under the urban selective pressures (pers. obs.). The likelihood of admixture between the sample populations both in the urban and meadow regions was minimal given the distance and the existence of roads and concrete structures between them.

Using a dissecting microscope with a micrometer scale, the radius of the pappus 'disk', length of the pappus 'beak', and length and width of the achene were measured for 10 random diaspores from each plant (Figure 1). Achene mass was measured with an electronic balance and achene volume determined assuming an ellipsoidal shape as described by Cody and Overton (1996). To estimate fall rates that are known to be related to the dispersal potential of achenes in the field (Cody \& Overton, 1996), the time taken for intact achenes to reach the ground after being dropped from a height of $2 \mathrm{~m}$ in still air conditions in the laboratory was recorded for 10 randomly chosen achenes per plant. The average time taken (sec) across 5 such drops for each diaspore was calculated (Brock, Weinig, \& Galen, 2005; Cody \& Overton, 1996; Sheldon \& Burrows, 1973). Fall rate of 50 pappus-removed achenes each from urban and meadow dandelions was also determined as described above. Achene, pappus and scape measurements as well as drop times were compared between sites by Student's t-test. Achenes from 50 randomly chosen meadow and urban plants were grown under common greenhouse conditions to compare their germination success, flower and diaspore characteristics. Common greenhouse conditions alleviate the maternal effects and allow us to determine the genetic bases of observed variations. Achenes were planted in 10-cm square pots with Promix potting soil and maintained at ambient light and temperature conditions. Pots were watered as required and monitored for germination, growth and flowering. Statistical analyses were performed using IBM SPSS Statistics 19 (SPSS Inc. Chicago, IL). 


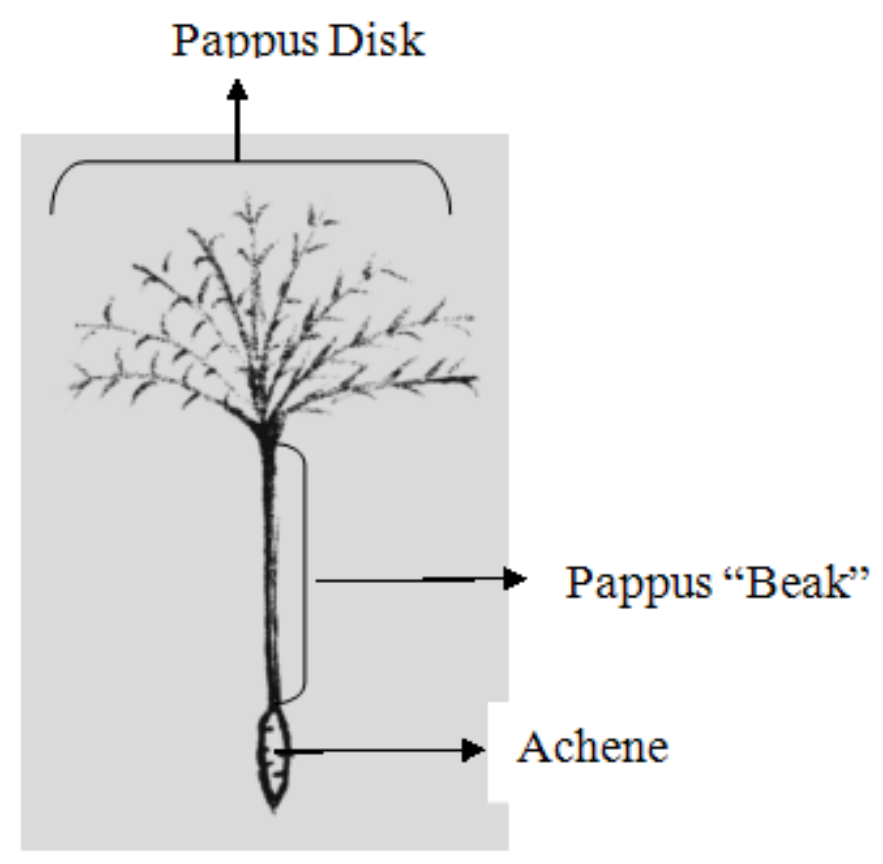

Figure 1. Schematic diagram of a dandelion dispersal unit showing the achene with pappus and the different morphological traits measured in the study

\section{Results}

Achenes from dandelion plants in the urban and meadow habitats exhibited distinct differences in dispersal and survival characteristics. Dispersal ability of the diaspores is dependent upon the pappus traits and a comparison between the urban and meadow dandelions indicated that the pappus beak was significantly longer in urban achenes (Figure 2; $\mathrm{t}_{279}=3.30 ; \mathrm{P}=0.0005$ ) but there was no difference in the radius of the pappus disk (Urban: $8.16 \pm 1.6 \mathrm{~mm} ; \mathrm{n}=135$; Meadow: $\left.7.72 \pm 1.6 \mathrm{~mm} ; \mathrm{n}=146 ; \mathrm{t}_{279}=1.90 ; \mathrm{P}=0.06\right)$. A comparison of fall rate of intact achenes under laboratory conditions, indicated that urban achenes dropped to the ground significantly faster than the meadow achenes (Figure $2 ; \mathrm{t}_{279}=4.79 ; \mathrm{P}<0.0001$ ) but the fall rate of pappus-removed urban achenes did not differ significantly from that of pappus-removed meadow achenes (Figure $2 ; t_{98}=0.93 ; \mathrm{P}=0.17$ ) In addition, the scape which provides a release height for the diaspores was significantly shorter in the urban dandelions than in meadow plants (Figure $2 ; \mathrm{t}_{279}=2.57 ; \mathrm{P}=0.01$ ). Correlation analyses of diaspore morphologies and dispersal ability indicated that the pappus beak length of urban achenes was significantly correlated with fall rates (Figure $3 ; \mathrm{r}=-0.21 ; \mathrm{n}=102 ; \mathrm{P}=0.03)$ but pappus width was not $(\mathrm{r}=0.12 ; \mathrm{n}=102 ; \mathrm{P}$ $=0.37$ ). However, neither the pappus beak (Figure $3 ; \mathrm{r}=-0.06 ; \mathrm{n}=106 ; \mathrm{P}=0.5$ ) nor the pappus width ( $\mathrm{r}=-$ $0.18 ; \mathrm{n}=106 ; \mathrm{P}=0.2$ ) were correlated with fall rates of meadow achenes.

The achenes from the two habitats also showed significant differences with respect to the survival and reproductive characteristics. There was no significant difference in the mass and volume of achenes from meadow and urban dandelions (Achene mass: Urban: $0.33 \pm 0.03 \mathrm{mg}$; Meadow: $0.32 \pm 0.13 \mathrm{mg} ; \mathrm{t}_{279}=1.65 ; \mathrm{P}=$ 0.09; Achene volume: Urban: $0.75 \pm 0.2 \mathrm{~mm}^{3}$; Meadow: $0.73 \pm 0.2 \mathrm{~mm}^{3} ; \mathrm{t}_{279}=0.53 ; \mathrm{P}=0.59$ ). Although achene germination success was generally high, $96 \%$ of urban achenes germinated as compared to $74 \%$ of meadow achenes $\left(\chi^{2}=9.49 ; \mathrm{df}=1 ; \mathrm{P}=0.02\right)$, flowering success under controlled conditions was low with only $40 \%$ of all the plants producing flowers with a significant difference between urban and meadow plants. $56 \%$ (27 out of 48 ) of plants grown from urban achenes went on to produce flowers while only $19 \%$ ( 7 out of 37 ) of those from meadow achenes did so $\left(\chi^{2}=12.13\right.$; $\left.\mathrm{df}=1 ; \mathrm{P}=0.0005\right)$. Plants grown from urban achenes also produced significantly higher number of flowers per plant (3.04 \pm 1.7$)$ as compared to those from meadow achenes $(1.71 \pm$ $0.7 ; \mathrm{t}_{23}=3.05 ; \mathrm{P}=0.005$ ) but the days to flowering (Urban: $74.35 \pm 21.5$ days; Meadow: $90.57 \pm 26.9$ days; $\mathrm{t}_{32}=$ $1.46 ; \mathrm{P}=0.1$ ) and fruit maturity (Urban: $9.8 \pm 3.9$ days; Meadow: $11.6 \pm 4.2$ days; $\mathrm{t}_{32}=0.99 ; \mathrm{P}=0.3$ ) were similar between the two. 


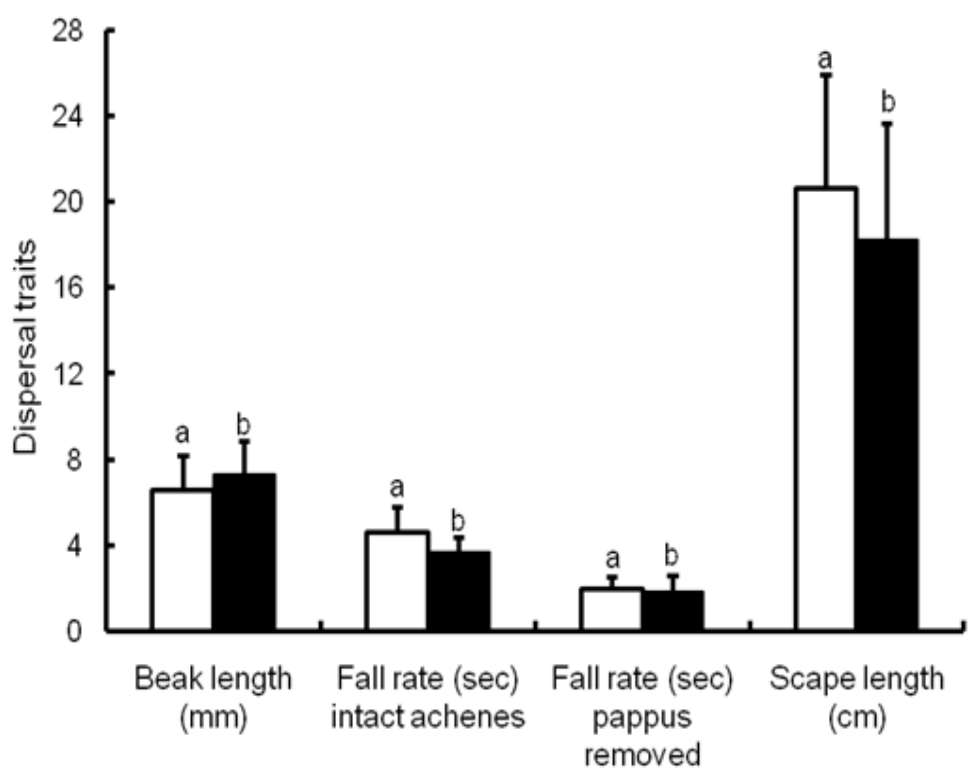

Figure 2. A comparison of dispersal traits (Mean $\pm \mathrm{SD}$ ) of achenes from urban and meadow habitats. Statistical comparisons are for each trait between the two habitats. Bars with different letters are significantly different

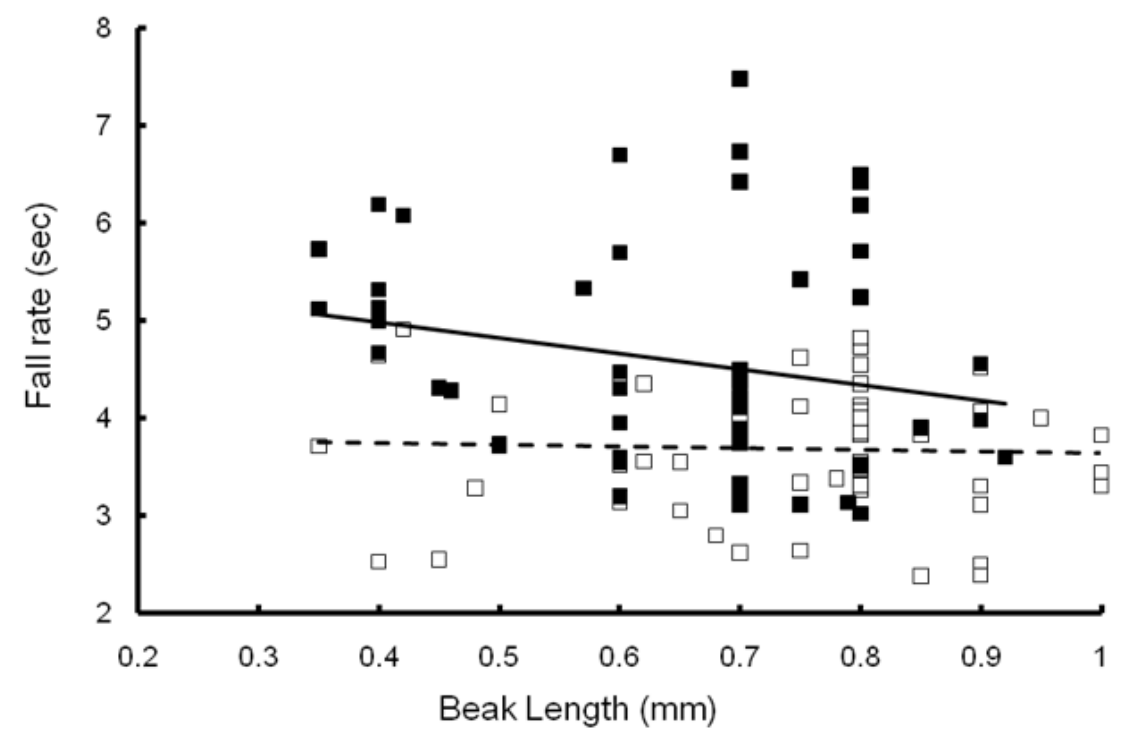

Figure 3. Relation between fall rate (sec) and pappus beak $(\mathrm{mm})$ of dandelion achenes from meadows and urban areas with the best fit line indicating the change in fall rate as a function of beak length in achenes from urban and meadow populations. Solid line represents the decreasing fall rate with increasing pappus beak as seen in urban achenes (Fall rate $=-1.62 *$ Beak length +5.64 ). The broken line indicates the lack of relation between the two variables in meadow achenes (Fall rate $=-0.18 *$ Beak length +3.81 )

\section{Discussion}

Morphological changes resulting from alterations in habitat structure are becoming increasingly common in plants, sometimes leading to extensive proliferance of weedy species that may be better adapted and more successful in urban areas (Aviron, Kindlmann, \& Burel 2007; Shochat et al., 2006; Steffan-Dewenter \& Tscharntke, 1999). In this study, the achenes from urban dandelions were borne on shorter scapes resulting in shorter release heights in the field which is advantageous in urban areas where achenes can survive only if they land close to the maternal plant. They also exhibited a quicker fall rate under laboratory conditions, a reliable 
measure for comparison of dispersal potential. Although terminal velocity of wind-dispersed seeds provides the distance travelled by seeds in the actual habitat, it depends on the ambient wind speeds that could vary immensely with time and regions. Quicker vertical fall rates under laboratory conditions have been interpreted as a measure of the dispersal potential of many winged seeds (Brock, Weinig, \& Galen, 2005; Burrows, 1973; Cody \& Overton, 1996; Sheldon \& Burrows, 1973; Tackenberg, Poschlod, \& Kahmen, 2003). While intact achenes from urban dandelions exhibited quicker fall rates, the pappus-removed achenes from urban and meadow dandelions under similar laboratory conditions were not different in their fall rates, confirming that these pappus traits are important determinants of dispersal potential. Thus, achenes from urban dandelions may be expected to travel shorter distances than the achenes from meadow dandelions. Studies on dispersal effectiveness have also shown that the height of fruit presentation is crucial in determining the distance to which seeds are carried, a decrease in the height of release results in seeds travelling shorter distances (Burrows, 1973; Sheldon \& Burrows, 1973). Shorter dispersal distances is advantageous to urban achenes because the probability of landing on unsuitable surfaces such as roads and sidewalks increases as they move farther away from the plant of origin. The actual dispersal distances of achenes from urban and meadow habitats were not assessed in this study but the quicker fall rates under laboratory conditions suggest that urban achenes may experience strongly reduced dispersal ability.

Studies have shown that the common dandelion, T. officinale, fits the definition of a successful weed by exhibiting highly plastic responses in vegetative, reproductive and dispersal-related traits that are far superior to the native congener T. ceratophorum (Brock, Weinig, \& Galen, 2005). With the current trend of extreme urbanization, ability of a plant to adapt to human-altered habitats is increasingly crucial for its survival (Shochat et al., 2006) and a successful urban plant will be one that can respond to this prevailing pressure. Evolution of traits favoring reduced dispersal requires a strong selective pressure such as high costs of dispersal. Determining these costs and the genetic variance and heritability of dispersal-related traits will provide a better understanding of their evolutionary potential. Increasing habitat fragmentation has resulted in increasingly smaller urban habitats and in some cases habitat sizes have been reduced to the size of a large pot and weeds growing in these pots have been shown to produce larger proportion of non-dispersing seeds (Cheptou et al., 2008). Detailed studies on habitat configuration in urban environments and the resulting costs on dispersing seeds will allow us to determine the evolutionary trajectory of dispersal related traits in dandelion populations.

Another recently evolved character that has increased the reproductive success of dandelion is that of apomictic reproduction that leads to clonal populations (Richards, 1973), and variation in these clonal populations is maintained by intermittent outcrossing with sexual forms (Dijk, 2003). Plants from urban and meadow achenes growing under controlled conditions in the greenhouse exhibited significant differences in these life history traits. While meadow achenes had reduced germination, the non-germinated seeds continued to have viability and in some cases germinated many months later suggesting that fitness could be accrued over a period of time since seeds that do not germinate immediately contribute towards a long term seed bank (Thompson, Bakker, Bekker, \& Hodgson, 1998). Plants from urban achenes also showed higher incidences of polycarpy and a shortened life cycle from germination to flower maturity, features that urban dandelions have been shown to have acquired as they have evolved into highly successful urban weeds (Dijk, 2003; Ogawa \& Mototani, 1991). Future research aimed at determining the genetic variance and heritability of survival and dispersal traits can provide a better understanding of the evolutionary potential of urban dandelions.

Although reduced dispersal appears to be a favored in species experiencing high dispersal mortality, studies on several species in both oceanic islands (Cody \& Overton, 1996) and fragmented habitats (Thomas, 2000) predict that these adaptations result in increased local extinctions, making repeated colonization necessary to maintain these populations. Recent studies reporting reduction in plant diversity despite traditional conservation measures have attributed this to dispersal failures and colonization deficits due to land use changes and consequent dispersal-unfriendly landscapes (Ozinga et al., 2009). Reduced dispersal and related local extinctions can also have cascading effects on the survival of other groups such as herbivores and pollinators that are directly dependent on these plants and their flowers (Steffan-Dewenter \& Tscharntke, 1999). In the current study, urban islands were generally found in narrow areas bordering roads and seeds that can germinate and grow successfully are those that landed on these nearby habitats generally less than $1 \mathrm{~m}^{2}$ in area. While the actual horizontal distances travelled by achenes was not measured, it has been demonstrated in other species that the highly fragmented area available for successful growth in the urban environment is a sufficiently strong selective pressure (Cheptou et al., 2008; Ozinga et al., 2009). Persistence of urban dandelion populations could also imply repeated recolonizations and possible prevalence of secondary modes of dispersal via awns on achenes and plume hairs on pappus that adhere to clothing. In their study, Cody and Overton (1996) while recording a 
decrease in pappus volume in island plants also suggest other features such as density of hairs and secondary plumes influencing dispersal potential. These traits may indeed be important in urbanized species experiencing increased interaction with humans but little is known about the expression and functionality of such traits. Further research on urban plant populations can provide important insights into features contributing to the increased success of weedy species and understanding such processes might be crucial for the management and maintenance of biodiversity.

\section{Acknowledgements}

Thanks to Celeste Holcomb and Samuel Mudd for their help with achene measurements and Colorado State University Research Support that helped fund the study and publication of the manuscript.

\section{References}

Aviron, S., Kindlmann, P., \& Burel, F. (2007). Conservation of butterfly populations in dynamic landscapes: The role of farming practices and landscape mosaic. Ecological Modelling, 205, 135-145. http://dx.doi.org/10.1016/j.ecolmodel.2007.02.012

Brock, M. T., Weinig, C., \& Galen, C. (2005). A comparison of phenotypic plasticity in the native dandelion, Taraxacum ceratophorum and its invasive congener, T. officinale. New Phytologist, 166, 173-183. http://dx.doi.org/10.1111/j.1469-8137.2004.01300.x

Burrows, F. M. (1973). Calculation of the Primary Trajectories of Plumed Seeds in Steady Winds with Variable Convection. New Phytologist, 72, 647-664. http://dx.doi.org/10.1111/j.1469-8137.1973.tb04414.x

Cheptou, P. O., Carrue, O., Rouifed, S., \& Cantarel, A. (2008). Rapid evolution of seed dispersal in an urban environment in the weed, Crepis sancta. Proceeding of the National Academy of Sciences of the United States of America, 105, 3796-3799.

Cody, M. L., \& Overton, J. M. (1996). Short-Term Evolution of Reduced Dispersal in Island Plant Populations. Journal of Ecology, 84, 53-61. http://dx.doi.org/10.2307/2261699

Dijk, P. J. V. (2003). Ecological and evolutionary opportunities of apomixis: insights from Taraxacum and Chondrilla. Proceedings of the Royal Society Biological Sciences Series B, 358, 1113-1121. http://dx.doi.org/10.1098/rstb.2003.1302

Hamilton, W. D., \& May, R. M. (1977). Dispersal in stable habitats. Nature, 269, 578-581. http://dx.doi.org/10.1038/269578a0

Kandori, I., Hirao, T., Matsunaga, S., \& Kurosaki, T. (2009). An invasive dandelion unilaterally reduces the reproduction of a native congener through competition for pollination. Oecologia, 159, 559-569. http://dx.doi.org/10.1007/s00442-008-1250-4

Levin, S. A., Muller-Landau, H. C., Ran, N., \& Jerome, C. (2003). The ecology and evolution of seed dispersal: a theoretical perspective. Annual Review of Ecology, Evolution and Systematics, 34, 575-604. http://dx.doi.org/10.1146/annurev.ecolsys.34.011802.132428

Lyman, J. C., \& Ellstrand, N. C. (1998). Relative contribution of breeding system and endemism to genotypic diversity: the outcrossing endemic Taraxacum californicum vs. the widespread apomict $T$. officinale (sensu lato). Madrono, 45, 283-289.

Ogawa, K., \& Mototani, I. (1991). Land-use Selection by Dandelions in the Tokyo Metropolitan Area, Japan. Ecological Research, 6, 233-246. http://dx.doi.org/10.1007/BF02347125

Ozinga, W. A., Romermann, C., Bekker, R. M., Prinzing, A., Tamis, W. L. M., Schaminee, J. H. J., ... \& Groenendael J. M. V. (2009). Dispersal failure contributes to plant losses in N W Europe. Ecology Letters, 12, 66-74. http://dx.doi.org/10.1111/j.1461-0248.2008.01261.x

Richards, A. J. (1973). The origin of Taraxacum agamospecies. Botanical Journal of the Linnean Society, 66, 189-211. http://dx.doi.org/10.1111/j.1095-8339.1973.tb02169.x

Ridley, H. N. (1930). The dispersal of plants throughout the world. Ashford, Kent, L. Reeve \& Co.

Roff, D. A. (1990). The evolution of flightlessness in insects. Ecological Monographs, 60, 389-421. http://dx.doi.org/10.2307/1943013

Sheldon, J. C., \& Burrows, F. M. (1973). The Dispersal Effectiveness of the Achene-Pappus Units of Selected Compositae in Steady Winds with Convection. New Phytologist, 72, 665-675. http://www.jstor.org/stable/2430954 
Shochat, E., Warren, P. S., Faeth, S. H., McIntyre, N. E., \& Hope ,D. (2006). From patterns to emerging processes in mechanistic urban ecology. Trends in Ecology and Evolution, 21, 186-191. http://dx.doi.org/10.1016/j.tree.2005.11.019

Steffan-Dewenter, I., \& Tscharntke, T. (1999). Effects of habitat isolation on pollinator communities and seed set. Oecologia, 121, 432-440. http://dx.doi.org/10.1007/s004420050949

Tackenberg, O., Poschlod, P., \& Kahmen, S. (2003). Dandelion seed dispersal: the horizontal wind speed does not matter for long distance dispersal - it is updraft! Plant Biology, 5, 451-454. http://dx.doi.org/10.1055/s-2003-44789

Thomas, C. D. (2000). Dispersal and extinction in fragmented landscapes. Proceedings of the Royal Society Biological Sciences Series B, 267, 139-145. http://dx.doi.org/10.1098/rspb.2000.0978

Thompson, K., Bakker, J. P., Bekker, R. M., \& Hodgson, J. G. (1998). Ecological Correlates of Seed Persistence in Soil in the North-West European Flora. Journal of Ecology, 86, 163-169. http://dx.doi.org/10.1046/j.1365-2745.1998.00240.x 